\title{
The L1-Type Cell Adhesion Molecule Neuroglian Influences the Stability of Neural Ankyrin in the Drosophila Embryo But Not Its Axonal Localization
}

\author{
Michael Bouley, Ming-Zhu Tian, Kerry Paisley, Yu-Chi Shen, Jyoti Dhar Malhotra, and Michael Hortsch \\ University of Michigan, Department of Cell and Developmental Biology, Ann Arbor, Michigan 48109-0616
}

\begin{abstract}
Ankyrins are linker proteins, which connect various membrane proteins, including members of the L1 family of neural cell adhesion molecules, with the submembranous actin-spectrin skeleton. Here we report the cloning and characterization of a second, novel Drosophila ankyrin gene (Dank2) that appears to be the result of a gene duplication event during arthropod evolution. The Drosophila L1-type protein neuroglian interacts with products from both Drosophila ankyrin genes. Whereas the previously described ankyrin gene is ubiquitously expressed during embryogenesis, the expression of Dank2 is restricted to the nervous system in the Drosophila embryo. The absence of
\end{abstract}

neuroglian protein in a neuroglian null mutant line causes decreased levels of Dank2 protein in most neuronal cells. This suggests that neuroglian is important for the stability of Dank2 protein. However, neuroglian is not required for Dank2 axonal localization. In temperature-sensitive neuroglian mutants in which neuroglian protein is mislocated at the restrictive temperature to an intracellular location in the neuronal soma, Dank2 protein can still be detected along embryonic nerve tracts.

Key words: ankyrins; cell adhesion molecule; cytoskeleton; Drosophila; neuroglian; neurons
Neuronal cells are highly polarized, and their soma, dendrites, and axons contain different sets of proteins (Craig and Banker, 1994). This uneven distribution of proteins leads ultimately to the restricted localization of cellular processes and the directed propagation of signaling events. Several cellular structures and components, such as barrier structures, lipid rafts, membrane sorting complexes, and cytoskeletal elements, have been implicated in the formation and maintenance of specialized membrane domains (Rodriguez-Boulan and Powell, 1992; Craig and Banker, 1994; Brown and London, 1998; Winckler and Mellman, 1999). Nevertheless, how proteins are retained in these specialized plasma membrane areas is not known.

One hypothesis centers on the ankyrin-mediated interaction between L1-type neural cell adhesion molecules (CAMs) and the actin-spectrin membrane skeleton as initiators of specialized membrane domains in neuronal cells (Lambert et al., 1997). L1-Type CAMs are members of the Ig superfamily and are involved in cellular interactions that link neural cells together or to extracellular matrix molecules (Hortsch, 1996). In contrast to vertebrates, Drosophila harbors only one L1-type gene, which is referred to as neuroglian (Hortsch, 2000). Alternative splicing generates two neuroglian protein forms, the $\mathrm{nrg}^{180}$ form being

\footnotetext{
Received Dec. 6, 1999; revised March 17, 2000; accepted March 17, 2000.

This work was supported by National Institute of Health Grant HD29388 and a grant from the Spinal Cord Research Foundation to M.H. We would like to thank Drs. Fritz Rathjen and Thomas Brümmendorf (Max-Delbrück-Centrum, Berlin, Germany) and Dr. Robert Chandler (Union College, Barbourville, KY) for reading this manuscript and for many useful comments. We are also indebted to Dr. Ron Dubreuil (University of Chicago, Chicago, IL) for providing the Dank1 reagents, Dr. Roger Jacobs (McMaster University, Hamilton, Canada) for his analysis of the immunocytochemical experiments involving Drosophila embryos, and Georg Borner (Fitzwilliam College, Cambridge, UK) for his help with sequencing some of the Dank2 cDNA clones.

Correspondence should be addressed to Michael Hortsch, Department of Cell and Developmental Biology, University of Michigan, Ann Arbor, MI 48109-0616. E-mail: hortsch@umich.edu.

Copyright (C) 2000 Society for Neuroscience $\quad 0270-6474 / 00 / 204515-09 \$ 15.00 / 0$
}

expressed on most neuronal cell bodies and many axonal tracts and the smaller nrg ${ }^{167}$ form in non-neuronal tissues and on glial cells (Hortsch et al., 1990a). Both neuroglian protein forms contain a short cytoplasmic segment, which forms a binding site for ankyrin (Hortsch et al., 1998a). In Drosophila S2 cells, neuroglian and human L1-CAM both direct the recruitment of ankyrin and other membrane skeleton components to sites of cell-cell contact (Dubreuil et al., 1996; Hortsch et al., 1998b).

Ankyrins serve as linker molecules between the membrane skeleton and the plasma membrane by binding to $\beta$-spectrin and a number of integral membrane proteins (Bennett and Gilligan, 1993; Nelson and Beck, 1999). The N-terminal 24 ankyrin repeat units bind to these membrane proteins and are followed by a $\beta$-spectrin-binding domain. The C-terminal "regulatory" ankyrin protein domain varies significantly between different ankyrins, and its functional significance is presently not understood. Only one ankyrin-type gene has been identified so far in Caenorhabditis elegans and Drosophila (Dubreuil and Yu, 1994; Otsuka et al., 1995). At least three ankyrin genes are known to exist in mammalian species, which are referred to as $\operatorname{ankyrin}_{R}, \operatorname{ankyrin}_{B}$, and ankyrin $_{G}$ (Nelson and Beck, 1999). Some protein isoforms from each of the three mammalian ankyrin genes are expressed in neuronal cells and are specifically localized to axons or somatodendritic regions (Kordeli and Bennett, 1991; Kordeli et al., 1995; Kunimoto et al., 1998). At nodes of Ranvier and axon initial segments, ankyrin ${ }_{\mathrm{G}}$ colocalizes with L1 family members (Davis et al., 1996). Several lines of evidence suggest that L1 family members are involved in initiating the formation of specific plasma membrane subdomains in neuronal cells and may at least be responsible for the localization of ankyrin over shorter distances (Lambert et al., 1997). This leaves the question unanswered as to whether or not L1-ankyrin interactions are also necessary for the proper localization of ankyrin proteins along axonal tracts. 


\section{MATERIALS AND METHODS}

Antibodies. Mouse polyclonal antiserum was generated against a glutathione $S$-transferase (GST)-Dank2 fusion protein. A $2.3 \mathrm{~kb}$ Bam HI/SalI Dank2 cDNA fragment [encoding amino acids 352-1096 of the Dank2 open reading frame (ORF)] was isolated from one of the $\lambda \mathrm{gt} 11$ bacteriophages and ligated into the pGST-4T-3 expression vector. The fusion protein was expressed as described by Smith and Johnson (1988), and the Triton X-100-insoluble portion was extracted with $8 \mathrm{M}$ urea as described by Nilsson and Abrahmsen (1990). After dialysis against PBS, the ureasoluble fraction was injected into mice for the generation of antisera.

The Drosophila anti-neuroglian monoclonal antibodies (mAbs) 1B7 and BP-104 have been described previously (Bieber et al., 1989; Hortsch et al., 1990a), and the affinity-purified rabbit anti-Drosophila ankyrin 1 serum (Dubreuil and Yu, 1994) was a gift from Dr. Ron Dubreuil (University of Chicago, Chicago, IL).

Fly strains. The neuroglian null $\left(\mathrm{nrg}^{1}\right)$ and the neuroglian temperaturesensitive $\left(\mathrm{nrg}^{3}\right)$ mutant fly stocks (Hall and Bieber, 1997) were kindly provided by Dr. Allan Bieber (Purdue University, West Lafayette, IN). Wild-type Drosophila melanogaster and FM7c-balanced rrg $^{1}$ stocks were maintained at ambient temperatures $\left(23-25^{\circ} \mathrm{C}\right)$ except where stated in the text, whereas the $\mathrm{nrg}^{3}$ mutant stock was kept at $19^{\circ} \mathrm{C}$ in an $\mathrm{X}$ chromosome homozygous state. For temperature-shift experiments, $n r^{3}$ mutant and wild-type control embryos were collected at $19^{\circ} \mathrm{C}$ and then shifted to the restrictive temperature of $29^{\circ} \mathrm{C}$ until they were dissected and fixed. Embryos were staged according to Campos-Ortega and Hartenstein (1985).

Whole-mount staining procedures and dissections. Whole-mount embryos and embryo fillets were prepared and immunostained as described by Hall and Bieber (1997) with the following exceptions. Embryos were fixed in heptane saturated with $3.7 \%$ formaldehyde in PEM $(0.1 \mathrm{M}$ PIPES, pH 6.95, 2 mM EGTA, and $1 \mathrm{~mm} \mathrm{MgSO}_{4}$ ). Where comparisons were made between wild-type and mutant embryos, both pools of embryos were processed simultaneously. For immunocytochemistry, 3,3'diaminobenzidine was used as the detection agent for HRP-conjugated secondary antibodies (Jackson ImmunoResearch, West Grove, PA). Stained embryos were examined and photographed using a Nikon Optiphot 2 microscope equipped with Nomarski optics.

Whole-mount in situ hybridizations. Single-stranded, digoxigeninlabeled sense and antisense DNA probes were made from a $1.7 \mathrm{~kb}$ SmaI/ClaI Dank2 cDNA fragment and a $1.5 \mathrm{~kb}$ EcoRI/PstI Dank1 cDNA fragment and used for whole-mount tissue in situ hybridizations to Drosophila embryos as outlined previously (Hortsch et al., 1990b).

Yeast two-hybrid experiments. Yeast two-hybrid experiments were performed as described previously (Dubreuil et al., 1996; Hortsch et al., 1998a). pAS1-CYH2 and pACTII control plasmids were kindly provided by J. Clemens (University of Michigan, Ann Arbor, MI). Yeast selection plates and media were made, and yeast transformations were performed using established protocols (Ausubel et al., 1988).

cDNA cloning and DNA sequence determination. A yeast two-hybrid assay was used to identify novel neuroglian-binding proteins. Using the pAS-CYH2-Nrg180 cyto construct that has been described by Dubreuil et al. (1996) as the bait plasmid a cDNA library from Drosophila first instar larvae (generously provided by J. Clemens) was screened. From $\sim 5 \times$ $10^{5}$ colonies screened, 40 gave a positive signal using the substrate 5-bromo-4-cloro-3-indolyl- $\beta$-D-galactopyranoside (Bartel et al., 1993). After further genetic tests, 15 clones were maintained, one of which gave a strong specific interaction with the GAL4-nrg ${ }^{180}$ fusion protein, which was similar in strength to that of the published Dank1 (Dubreuil et al., 1996). The length of the cDNA insert was $\sim 1.2 \mathrm{~kb}$, encompassing amino acids $165-517$ of the complete Dank2 ORF. All other positive colonies contained identical cDNA inserts. Because they only reacted weakly with the GAL4-nrg ${ }^{180}$ fusion protein and were derived from the Drosophila gene for Fat-Body Protein-1, these cDNA fragments were not considered for further analysis.

The complete cDNA sequence of the $4.8 \mathrm{~kb}$ Dank2 transcript was assembled from several different cDNA clones. These were either isolated from a randomly primed Drosophila embryonic $\lambda$ gt 11 cDNA library (kindly provided by Dr. K. Zinn, California Institute of Technology, Pasadena, CA) or from a Drosophila expressed sequence tag (EST) cDNA clone GH01626 that was obtained from Research Genetics (Huntsville, AL). The 5' 870 bp of the Dank2 transcript were cloned using a $5^{\prime}$ rapid amplification of cDNA ends kit (RACE System kit; Life Technologies Rockville, MD). Using automatic Applied Biosystems (Foster City, CA) DNA Sequencers, the University of Michigan DNA Sequencing core performed all DNA sequence determinations.
Gal4 DNA-binding domain constructs (pAS1-CYH2)

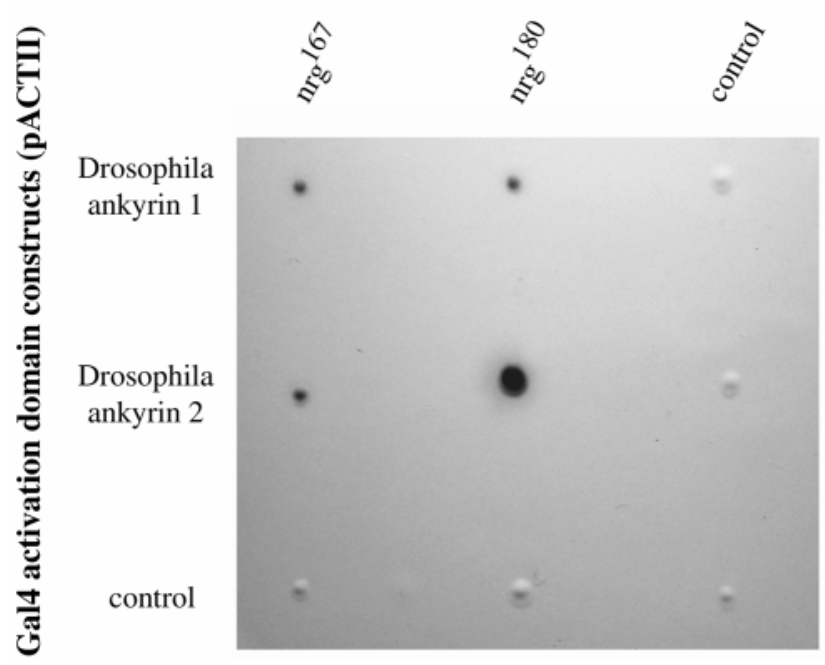

Figure 1. In a yeast two-hybrid experiment, Dank1 and Dank2 interact with both neuroglian cytoplasmic domain forms. cDNA fragments encoding all of the 24 ankyrin repeats of Dank1 and Dank2, respectively, were subcloned into the pACTII vector and cotransfected into Y190 yeast cells with pAS1-CYH2 plasmid DNA, which contained cDNA inserts encoding the cytoplasmic domain of the neuroglian ${ }^{167}$ or the neuroglian ${ }^{180}$ protein form. Control plasmids contained unrelated cDNA inserts. Transfected yeast cells were selected in the absence of tryptophan and leucine and tested for the induction of $\beta$-galactosidase, indicating an interaction between the two GAL4 fusion proteins.

Western blot procedure. Membrane proteins from 24 to $29 \mathrm{hr}$ Drosophila embryos, which were maintained at $19^{\circ} \mathrm{C}$, were prepared by a method previously described by Hortsch (1994) with the following modifications. Embryos were homogenized in $4-5$ vol of cold sucrose buffer $(0.32 \mathrm{M}$ sucrose, 2 mm sodium EGTA, pH 7.5, and $1 \mathrm{~mm}$ sodium azide, containing protease inhibitors) and spun at low speed $(900 \times g)$ for $10 \mathrm{~min}$. The supernatant was subsequently centrifuged at $17,000 \times g$ for $30 \mathrm{~min}$. DTT $(0.5 \mathrm{~mm})$ and sodium EGTA $(2 \mathrm{~mm})$ were added to the membrane pellet wash buffers. Membranes were stored in phosphate buffer at $-80^{\circ} \mathrm{C}$. Protein concentrations were determined by the Bradford method (Bradford, 1976) using bovine serum albumin fraction V (Sigma, St. Louis, $\mathrm{MO})$ as a standard. Proteins were separated by SDS-PAGE on $7.5 \%$ acrylamide gels, and immunoblots were performed using a modification of the procedure developed by Burnette (1981) according to Hortsch et al. (1985). Blots were treated with the enhanced chemiluminescence ECL Western Blotting System from Amersham Pharmacia Biotech (Uppsala, Sweden) and then exposed to Kodak X-Omat film (Eastman Kodak, Rochester, NY).

Northern blot procedure. Total RNA was prepared from S2 cells and from different Drosophila developmental stages and separated in formaldehyde containing $1 \%$ agarose gels (Lehrach et al., 1977) before being transferred to Hybond N+ Nucleic Acids Transfer Membranes from Amersham Pharmacia Biotech. Hybridizations were performed according to the method of Church and Gilbert (1984) using ${ }^{32}$ P-labeled DNA probes that were prepared with a Random Primer Extension System kit from NEN (Boston, MA). Probes for Dank1 were derived from a 5' $1 \mathrm{~kb}$ EcoRI cDNA fragment and probes for Dank2 from an internal $1.1 \mathrm{~kb}$ XhoI/BglII cDNA fragment.

\section{RESULTS}

\section{Cloning and molecular characterization of a second Drosophila ankyrin}

A Drosophila cDNA fragment encoding a polypeptide that strongly interacts with both Drosophila neuroglian protein forms was isolated from a Drosophila early larval library using a yeast two-hybrid approach (Fig. 1). The bait plasmid contained the entire cytoplasmic domain of the neuronal Drosophila neuroglian protein form $\left(\mathrm{nrg}^{180}\right)$. The single isolated, interacting library 
$\mathrm{G} \cdot \mathrm{TPLH} \cdot \mathrm{AA} \cdot \mathrm{GH} \cdot \mathrm{GV} \cdot \mathrm{LLL} \cdot \cdot \mathrm{GA} \cdot \mathrm{N} \cdot \mathrm{T} \cdot$ ankyrin repeat consensus

$\begin{array}{ll}\text { NH }_{2} \text {-MVTENGAQGD- } & \text { pre-ankyrin repeat segment } \\ \text { GNTSFLRAARAGNLERVLEHLKNNIDINTSNAN } & 1 \text { ankyrin repeats } \\ \text { GLNALHLASKDGHIHVVSELLRRGAIVDSATKK } & 2 \\ \text { GNTALHIASLAGQEEVVKLLLEHNASVNVQSQN } & 3 \\ \text { GFTPLYMAAQENHDAVVRLLLSNGANQSLATED } & 4 \\ \text { GFTPLAVAMQQGHDKVVAVLLESDTRGKV--- } & 5 \\ \text { RLPALHIAAKKDDVKAATLLLDNDHNPDVTSKS } & 6 \\ \text { GFTPLHIASHYGNQNIANLLIQKGADVNYSAKH } & 7 \\ \text { NISPLHVAAKWGKTNMVSLLLEKGGNIEAKTRD } & 8 \\ \text { GLTPLHCAARSGHEQVVDMLLERGAPISAKTKN } & 9 \\ \text { GLAPLHMAAQGEHVDAARILLYHRAPVDEVTVD } & 10 \\ \text { YLTALHVAAHCGHVRVAKLLLDRNADANARALN } & 11 \\ \text { GFTPLHIACKKNRLKVVELLLRHGASISATTES } & 12 \\ \text { GLTPLHVAAFMGCMNIVIYLLQHDASPDVPTVR } & 13 \\ \text { GETPLHLAARANQTDIIRILLRNGAQVDARARE } & 14 \\ \text { QQTPLHIASRLGNVDIVMLLLQHGAQVDATTKD } & 15 \\ \text { MYTALHIAAKEGQDEVAAVLIENGAALDAATKK } & 16 \\ \text { GFTPLHLTAKYGHIKVAQLLLQKEADVDAQGKN } & 17 \\ \text { GVTPLHVACHYNNQQVALLLLEKGASPHATAKN } & 18 \\ \text { GHTPLHIAARKNQMDIATTLLEYGALANAESKA } & 19 \\ \text { GFTPLHLSSQEGHAEISNLLIEHKAAVNHPAKN } & 20 \\ \text { GLTPMHLCAQEDNVNVAEILEKNGANIDMATKA } & 21 \\ \text { GYTPLHVASHFGQANMVRFLLQNGANVDAATSI } & 22 \\ \text { GYTPLHQTAQQGHCHIVNLLLEHKANANAQTVN } & 23 \\ \text { GQTPLHIARKLGYISVLDSLKTITKEDETAAA- } & 24 \text { spectrin binding domain: } \\ \text { PSQAEEKYRVVAPEAMHESFMSDSEEEGGEDNMLSDQPYRY acidic region } \\ \text { LTVDEMKSLGDDSLPIDVTRDERMDSNRMTQSAEYASGVPP } \\ \text { TIGEEVISPHKTQVYGSSPKATVDGVYIANGSGHDEPPHVG basic region } \\ \text { RKLSWKSFLVSFLVDARGGAMRGCRHSGVRMIIPSRSTCQP } \\ \text { TRVTCRYVKPQRTMHPPQLMEGEALASRVLELGPCSTKFIG } \\ \text { PVVMEVPHFASLRGKEREIIILRSDNGETWREHTIDNSEEI } \\ \text { IHDVLQQCFEPEEIAQLEEQAGNHVCRFVTYDFPQYFAVVS } \\ \text { RIRQEVHAIGPEGGMVSSTVVPQVQAVFPQGALTKKIKVGL } \\ \text { QVNLFKPRKGVAPEKIRKISVNHVPKKKRFSLIW-COOH } \\ \end{array}$

Figure 2. Amino acid sequence of the Dank2 ORF. The Dank2 protein is encoded by a 1159 amino acid residue ORF that is encoded by a $4.8 \mathrm{~kb}$ transcript. The cDNA sequence of the Dank2 transcript is available from GenBank under accession number AF190635. The N-terminal 24 ankyrin repeats are preceded by a 10 amino acid preankyrin segment and have been aligned below the ankyrin repeat consensus sequence. The spectrin-binding domain is encoded by 362 amino acids with an $\mathrm{N}$-terminal 82 amino acid residues acidic domain, which is followed by a 280 amino acid residues basic region. plasmid contained a $1.1 \mathrm{~kb}$ cDNA insert that encoded $10 \mathrm{com}-$ plete and two partial ankyrin-type repeat units (33 amino acids per repeat, representing amino acid residues $165-516$ of the complete ORF) (Fig. 2). The sequence determination of additional Drosophila cDNA clones from a late embryonic cDNA library and of a Drosophila EST clone (EST number GH01626) indicated that the original insert represents part of a larger transcript (GenBank accession number AF190635), which is derived from a novel Drosophila ankyrin gene. The complete ORF encodes a 1159 amino acid residues polypeptide with 24 $\mathrm{N}$-terminal ankyrin repeats and a C-terminal 362 amino acid spectrin-binding domain (Fig. 2). Throughout the entire ORF, this novel Drosophila ankyrin species exhibits a strong homology to the Drosophila ankyrin transcript that was previously described by Dubreuil and Yu (1994). At the amino acid level, the two Drosophila ankyrins are $66.2 \%$ identical over the ankyrin repeat domain and 36 and $51.7 \%$ identical over the acidic and basic part of the spectrin-binding domain. Because both Drosophila ankyrin proteins are derived from different genes that are located on the fourth (101F-102A) and third (66A) chromosome (Dubreuil and Yu, 1994; data not shown), respectively, we will subsequently refer to them as Drosophila ankyrin 1 (Dank1) and Drosophila ankyrin 2 (Dank2).

A phylogenetic analysis of all currently known vertebrate and invertebrate ankyrin genes, for which sufficient sequence information is available, indicates that the two Drosophila ankyrin genes do not represent orthologs of any of the three so far identified vertebrate ankyrin paralog groups (Fig. 3). Rather,

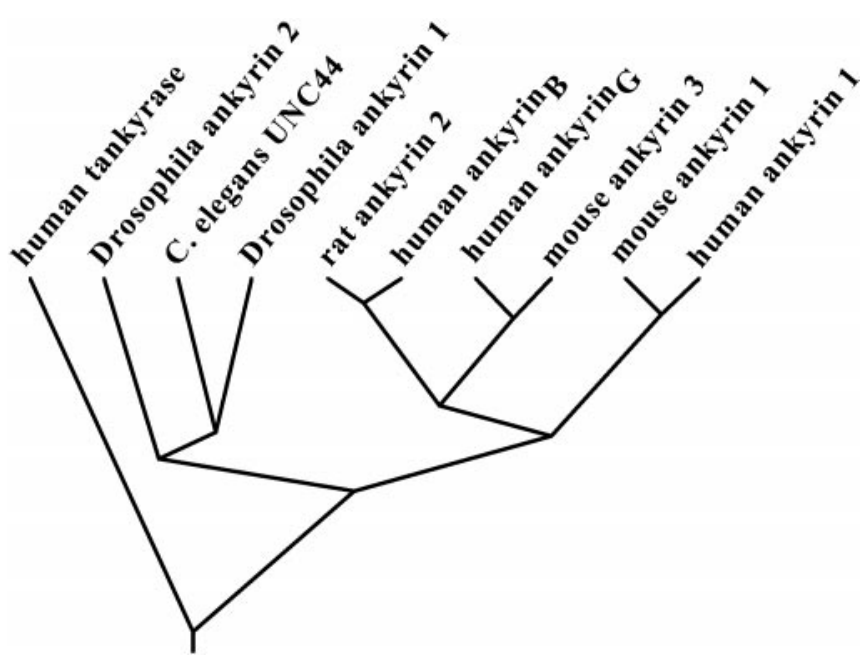

Figure 3. Phylogenetic analysis of proteins with 24 ankyrin repeats. The phylogenetic tree was constructed for all known proteins with 24 ankyrin repeats for which sufficient sequence information is available from GenBank. Human tankyrase is a telomere-associated protein with 24 ankyrin repeats but without a spectrin-binding domain (Smith et al., 1998). It serves as an out-group sequence in this analysis. After aligning the cDNA sequence segments encoding the 24 ankyrin repeats using the multiple alignment feature of the MacDNASIS Pro 3.0 program package (Hitachi Software, South San Francisco, CA) (Higgins-Sharp algorithm), a rooted phylogenetic tree was constructed using the DNAMLK and DRAWGRAM programs of the PHYLIP program package. 
A

B

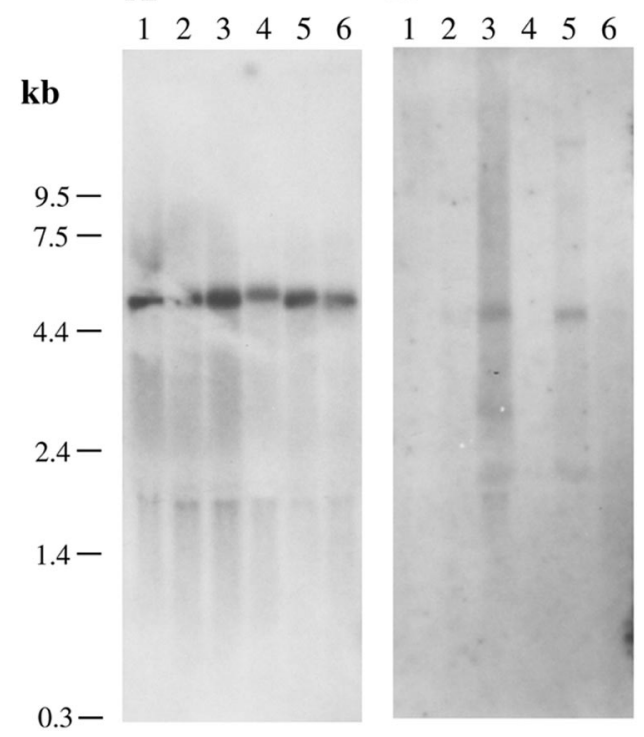

Figure 4. Developmental Northern blots for Drosophila ankyrins. Total RNA $(40 \mu \mathrm{g})$ was separated on a $1 \%$ formaldehyde agarose gel and blotted onto nylon membranes, which were probed with ${ }^{32} \mathrm{P}$-labeled DNA probes specific for either Dank1 $(A)$ or Dank2 $(B)$. Lanes 1 contain RNA isolated from Drosophila S2 tissue culture cells, lanes 2 from 0-12 hr embryos, lanes 3 from 12-24 hr embryos, lanes 4 from larvae, lanes 5 from pupae, and lanes 6 from adult flies.

independent gene duplication events during the evolution of the arthropod and chordate lineages have resulted in multiple ankyrin genes in Drosophila and in mammalian species.

A Northern blot analysis indicates that the two Drosophila ankyrin genes exhibit different expression patterns during Drosophila development (Fig. 4). The major Dank1 gene product is a $5.5 \mathrm{~kb}$ transcript that is evenly expressed throughout the entire life cycle of the fly and also in Drosophila S2 tissue culture cells (Fig. 4A). In contrast, the Dank2 gene is only expressed during the second half of embryogenesis and during the larval stage (Fig. $4 B$ ) when neuronal differentiation takes place in Drosophila. The assembled cDNA sequence for Dank2 (GenBank accession number AF190635) corresponds in size to the major transcript of 4.8 $\mathrm{kb}$, which is detected by Dank2 cDNA probes on Northern blots of Drosophila RNA (Fig. 4B).

The Dank1 transcript is translated into a single polypeptide with an apparent molecular weight of $170 \mathrm{kDa}$ that can be detected by Dank1-specific antibodies in membrane preparations from Drosophila embryos (Fig. 5, lane 1). Anti-Dank2 antibodies react with a major membrane-associated protein of $\sim 137 \mathrm{kDa}$ (Fig. 5, lane 2), which agrees well with the Dank2 ORF predicted molecule mass (125.764 Da) shown in Figure 2. In some membrane preparations, several additional smaller protein bands, which appear to be degradation products of the intact Dank2 protein, were also detected by Dank2-specific antisera.

\section{Neuron-specific expression of Drosophila ankyrin 2 during embryogenesis}

In situ hybridization experiments and the immunocytochemical detection of Dank2 protein using mouse polyclonal antisera demonstrated that, in the Drosophila embryo, Dank2 gene expression is restricted to the developing nervous system (Fig. 6A-D). Beginning at embryonic developmental stage 11, Dank2 transcript and protein can first be detected along the extended germ band

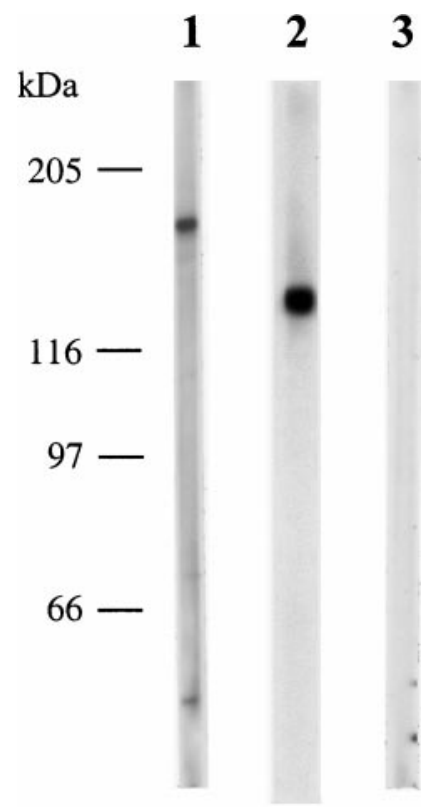

Figure 5. Western blot analysis of Drosophila ankyrins. Shown are Western blots of Drosophila embryonic membrane proteins $(30 \mu \mathrm{g}$ of total protein per lane), which were separated on $7.5 \%$ SDS-PAGE and probed with a mouse anti-Dank 1 antiserum (lane 1), a mouse anti-Dank2 antiserum (lane 2), or a mouse nonimmune serum (lane 3).
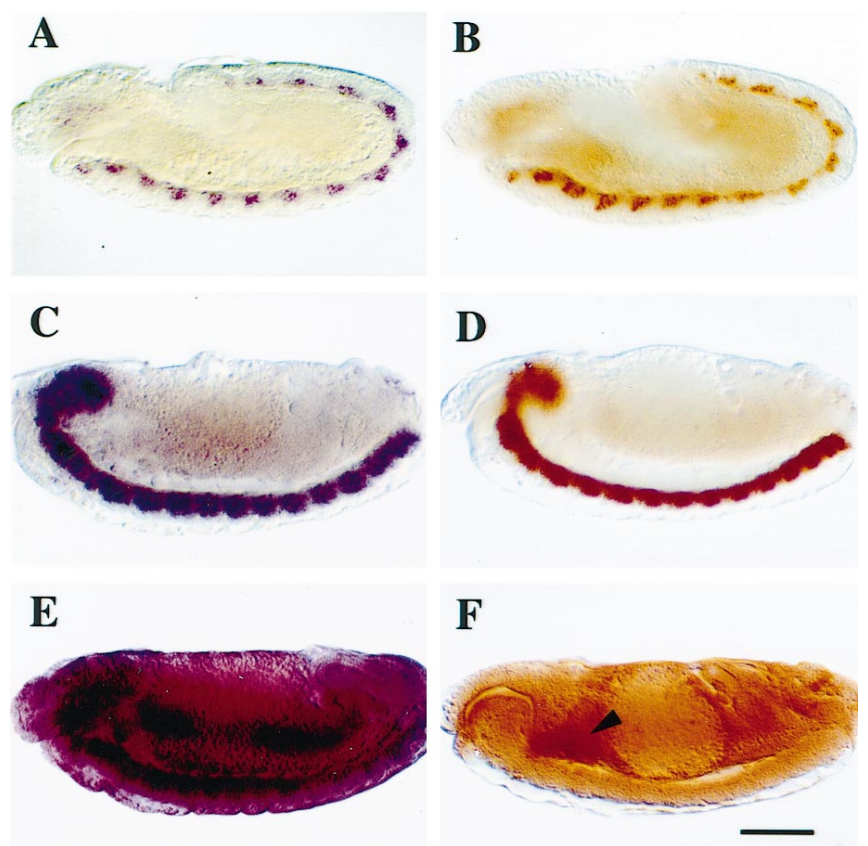

Figure 6. Dank2 expression is confined to the developing nervous system in Drosophila embryos. The expression of ankyrins in developing Drosophila embryos was visualized by in situ hybridization using DNA probes specific for Dank2 $(A, C)$ or for Dank1 $(E)$ or by immunocytochemistry using mouse anti-Dank2 $(B, D)$ or rabbit anti-Dank1 antibodies $(F)$. $A$ and $B$ depict midstage 11 embryos, whereas $C-F$ show stage 14 embryos. The arrowhead in $F$ indicates the salivary gland anlage. PNS staining is out of the plane of focus and therefore not visible in these panels. Anterior is to the left. Scale bar, $120 \mu \mathrm{m}$. 

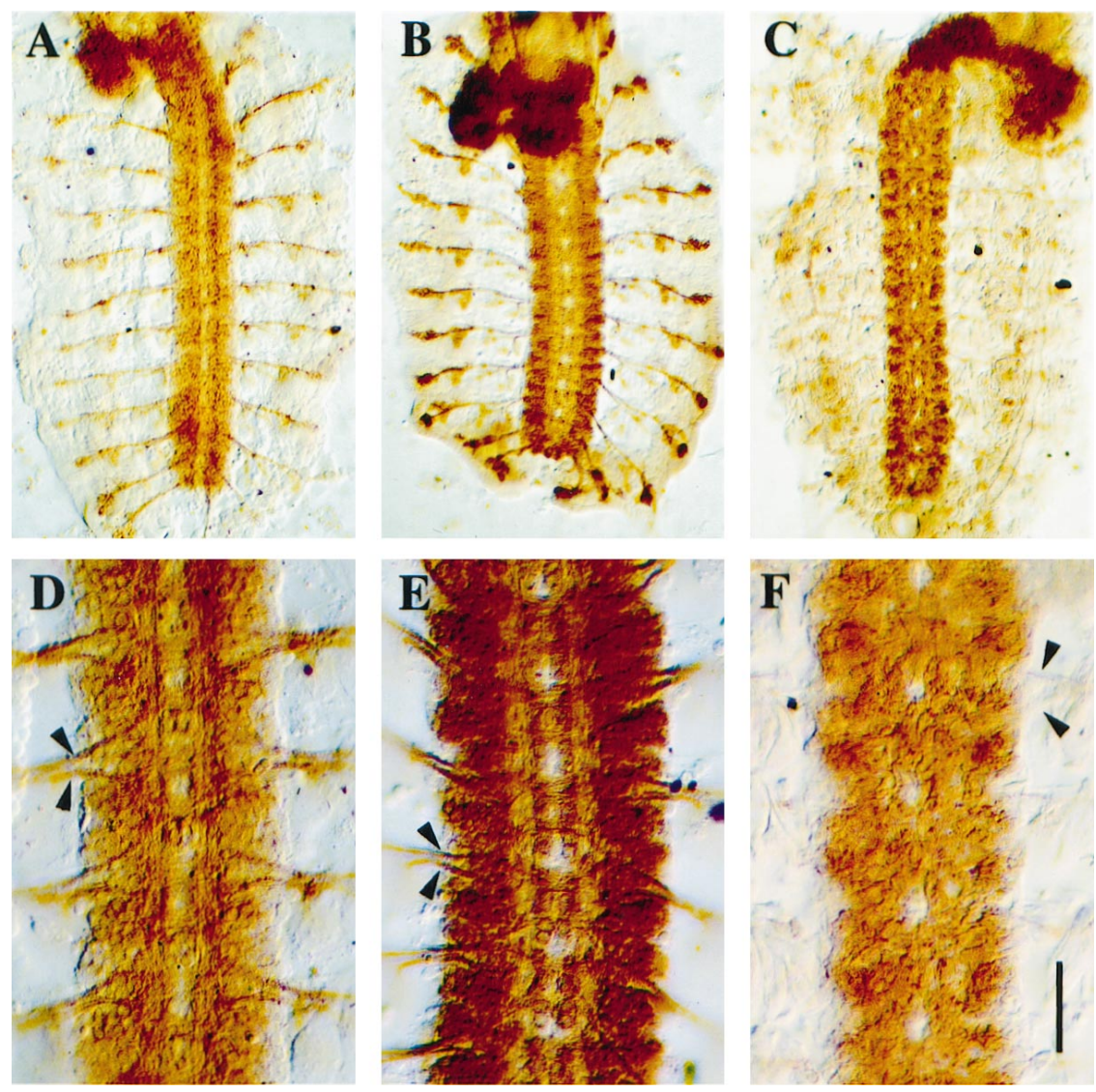

Figure 7. Dank2 and the neuronal, $\operatorname{nrg}{ }^{180}$ protein form are coexpressed in the Drosophila embryonic nervous system, and the absence of neuroglian protein decreases the level of Dank2 in embryonic neurons and nerve tracts. Shown are dissections of Drosophila embryos, which were stained using either the anti-nrg ${ }^{180}$ mAb BP-104 $(A, D)$ or a mouse anti-Dank2 antiserum $(B, C, E, F) . D-F$ represent larger magnifications of the embryos in $A-C$. Whereas the dissections shown in $A$ and $D$ versus $B$ and $E$ are from wild-type embryos, the embryo in $C$ and $F$ is a homozygous mutant for neuroglian $\left(n r^{l}\right)$. The arrowheads in $D-F$ indicate the axons of the segmental and intersegmental nerves. To discriminate between heterozygous and homozygous neuroglian mutant embryos, dissections were first stained with the anti-neuroglian mAb 1B7, and unstained embryos were subsequently incubated with anti-Dank2 antibodies. Scale bar: $A-C, 120 \mu \mathrm{m} ; D-F$, $40 \mu \mathrm{m}$. during the commencement of neuronal differentiation (Fig. $6 A, B)$. As shown in Figure $6, C$ and $D$, during germ band retraction, Dank2 staining becomes more intense in the maturing ventral nerve cord and also appears in the developing PNS (not in the plane of focus in Fig. $6 C, D$ ) and the brain hemispheres. In contrast to the confined nervous system expression of Dank2, Dank1 mRNA and protein expression appears to be ubiquitous throughout the Drosophila embryo (Fig. $6 E, F$ ). The only tissue exhibiting an increased Dank1 protein level during embryonic developmental stage 14 is the salivary gland anlage (Fig. 6F, arrowhead).

The panneuronal expression pattern of the Dank2 gene results in an almost complete overlap throughout the PNS and CNS with the expression pattern of the neuronal protein form of the Drosophila CAM neuroglian. As demonstrated by the immunodetection of $\operatorname{nrg}^{180}$ using the mAb BP-104 and of Dank2 protein by polyclonal mouse antisera in dissected Drosophila embryos, both molecules are coexpressed in a majority of peripheral, as well as central, neuronal cell bodies and axon tracts (Fig. 7, $A$ and $D$ vs $B$ and $E$ ). However, one group of neuronal cells that expresses Dank2 protein but is devoid of BP-104 staining for neuroglian is the ventral unpaired medial neurons (VUMs) along the midline of the developing ventral nerve cord (Fig. $8 A, C$ ). These neuronal cells express the transcription factor engrailed, which acts as a negative regulator of neuroglian expression (Siegler and Jia, 1999). Nevertheless, in wild-type embryos Dank2 staining in the VUMs remains strong and confined to areas of cell-cell contact (Fig. 8A, arrowheads), indicating that these cells express an as yet unknown membrane receptor for Dank2 that is different from neuroglian.

\section{Drosophila neuroglian is required for Dank2 protein stability}

To study the role of neuroglian as a membrane receptor for Dank2 in vivo, Dank2 expression and localization was examined in Drosophila embryos with different mutations in the neuroglian gene. In $\mathrm{nrg}^{1}$ mutant embryos, neuroglian immunostaining is completely absent, resulting in late embryonic lethality and a number of neurological defects (Bieber et al., 1989; Hall and Bieber, 1997). Therefore, immunostaining with the antineuroglian mAb 1B7 (Bieber et al., 1989) was used as a means for identifying homozygous, $\mathrm{nrg}^{1}$ mutant embryos. Embryos that did not react with the $1 \mathrm{~B} 7 \mathrm{mAb}$ were subsequently stained with anti-Drosophila ankyrin 2 antisera. As shown in Figure 7, $B$ and $E$ versus $C$ and $F$, embryos lacking neuroglian exhibited a significantly reduced level of Dank2 staining. Some remaining Dank2 immunoreactivity was still visible in the dense population of neuronal cell bodies in the nerve cord. However, Dank2 protein was below or near the limit of detection in the longitudinal and commissural axonal tracts of the ventral nerve cord, the cell bodies of the PNS, and the peripheral nerve roots (Fig. $7 F$, arrowheads).

If this reduction of Dank2 staining was a result of the lack of neuroglian protein in these cells, then the level and the localization of Dank2 in VUM neurons, which normally do not express neuroglian, should remain unchanged. As depicted in Figure $8 B$, Dank2 expression in the VUMs of $\mathrm{nrg}^{1}$ homozygous embryos remained at wild-type levels and localized to cell-cell contact areas. In contrast, the cell bodies of most lateral neurons in the ventral nerve cord of these mutant embryos not only exhibited reduced levels of Dank2 protein, but the Dank2 immunostaining 

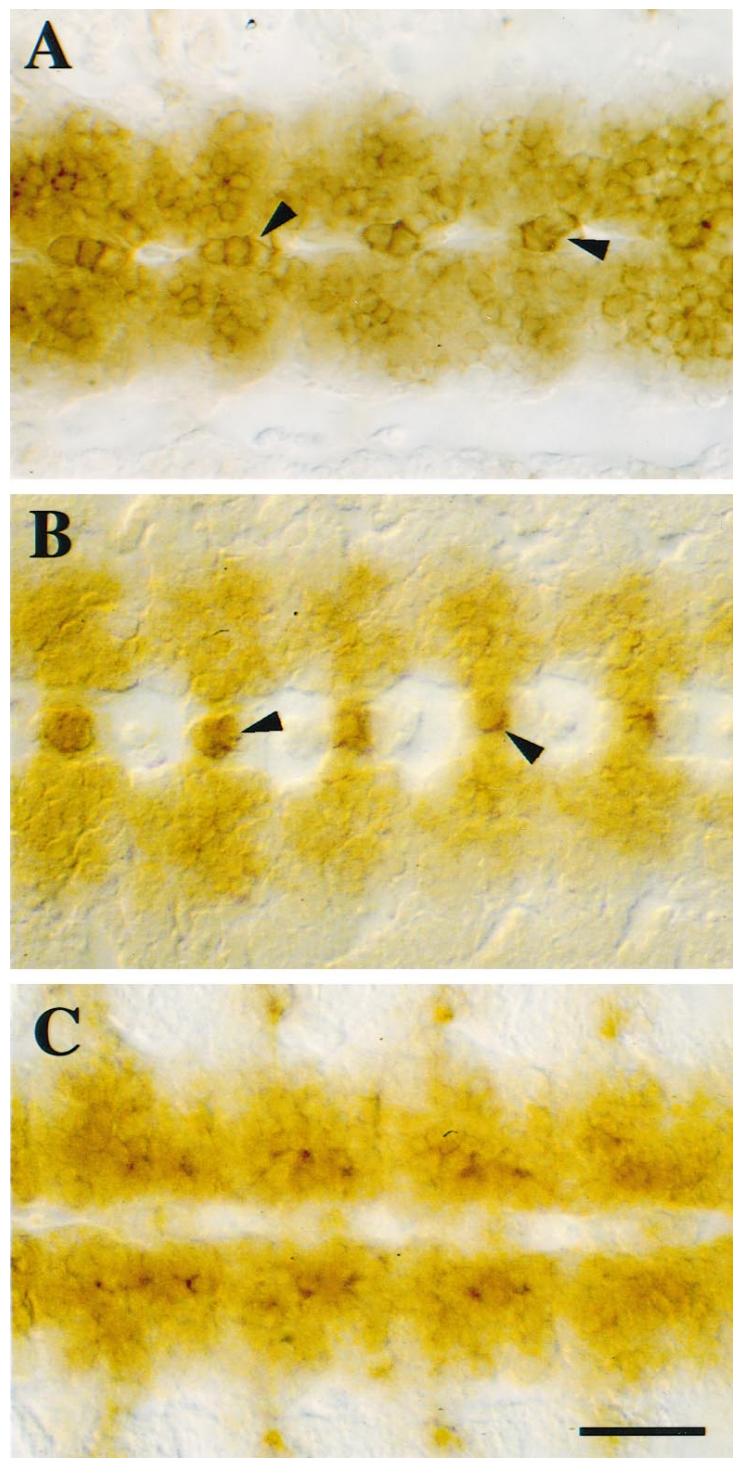

Figure 8. In contrast to most other CNS neurons, midline neurons maintain high levels of Dank2 protein at cell contact sites in neuroglian protein-null embryos. Shown is a comparison of Dank2 immunostaining in the ventral nerve cord of stage 13 Drosophila embryos. $A$ depicts a wild-type embryo, whereas the embryo in $B$ does not express neuroglian protein (indicated by the absence of $1 \mathrm{~B} 7 \mathrm{mAb}$, neuroglian-specific immunostaining). Arrowheads indicate groups of midline neuronal cells (VUMs). $C$ depicts the distribution of the neuronal neuroglian form $\left(\mathrm{nrg}^{180}\right)$ in the ventral nerve cord at embryonic stage 13. Scale bar, $40 \mu \mathrm{m}$.

also appeared more diff use and was not concentrated at cell-cell contact sites. In contrast to Dank2, immunostaining experiments using anti-Dank1 antibodies on wild-type and $\mathrm{nrg}^{1}$ mutant embryos revealed no detectable differences in the amount or distribution of Dank1 protein (data not shown).

To determine whether the reduction of Dank2 staining in neuroglian-deficient embryos was a pretranslational or posttranscriptional process, Dank2 mRNA levels in the PNS of wild-type versus $\mathrm{nrg}^{1}$ mutant embryos were analyzed by in situ hybridization (Fig. 9A,C). In contrast to the decrease of the Dank2 protein level (Fig. 9B,D), no significant reduction in Dank2 mRNA was observed in $\mathrm{nrg}^{1}$ homozygous embryos (Fig. 9C).

In the wild-type embryonic PNS, Dank2 protein is initially expressed in all cell bodies of the lateral sensory organs (Fig. 8B).
Not until the beginning of developmental stage 14 can Dank2 protein also be detected in the peripheral axonal tracts and in the dendritic extensions of peripheral sensory neurons (Fig. 9E). This is in contrast to the nrg ${ }^{180}$ polypeptide, which can be visualized in the peripheral sensory pathways before Dank2 staining becomes evident (Fig. 9, $B$ vs $G$ ).

\section{Axonal localization of Dank2 does not depend on Drosophila neuroglian expression}

Whether the axonal localization of Dank2 protein depends on the cellular localization of neuroglian was determined using a conditional neuroglian mutant. In embryos, which are homozygous for this temperature sensitive mutation $\left(\mathrm{nrg}^{3}\right)$ and which are raised at the restrictive temperature $\left(29^{\circ} \mathrm{C}\right)$, neuroglian protein is not properly transported to the plasma membrane and remains in an intracellular localization (Hall and Bieber, 1997). As a result of this mislocalization of neuroglian protein, such mutant embryos exhibit the same embryonic lethality and altered motoneuron pathfinding trajectories as the $\mathrm{nrg}^{1}$ mutant embryos. Figure $10 \mathrm{~B}$ demonstrates that, in $\mathrm{nrg}^{3}$ mutant embryos, which were reared at the nonpermissive temperature, neuroglian protein is restricted to the cell bodies of peripheral sensory neurons and is absent from their axonal extensions. This intracellular, mislocalized neuroglian protein was able to rescue the decrease of Dank2 protein levels that was observed in neuroglian-deficient embryos (Figs. 7-9). Despite the absence of neuroglian protein in axonal tracts, Dank2 protein was correctly transported and localized to peripheral axonal pathways in $\mathrm{nrg}^{3}$ embryos, which were incubated at $29^{\circ} \mathrm{C}$ (Fig. $10 D$ ). In wild-type embryos, the elevated temperature had no influence on the proper localization of either neuroglian or Dank2 protein to the cell bodies, as well as the axonal extensions of peripheral sensory neurons (Fig. 10A,C).

\section{DISCUSSION}

This study describes the identification and characterization of a second Drosophila ankyrin gene. In contrast to the Drosophila ankyrin gene that has been described previously by Dubreuil and Yu (1994), the expression of Dank2 is restricted to neuronal cells during embryogenesis. The L1-type CAM neuroglian appears to be an important binding partner of Dank2 in these cells, and this interaction is essential for the maintenance of Dank2 protein levels in the developing nervous system. However, the axonal localization of Dank2 protein is independent of neuroglian protein being present along axonal tracts, indicating that this interaction is not required for Dank2 protein to be transported from the soma to axonal locations.

The finding of two ankyrin genes in Drosophila is somewhat unexpected. For many vertebrate gene families, which often consist of several paralogous members, only a single Drosophila ortholog has been described (Pebusque et al., 1998). This has been interpreted as an indication that, during chordate evolution, two genome duplication events have generated multiple paralogous genes from a single ancestral gene that is still found in arthropod species. The Dank2 gene not only differs from the ankyrin gene described by Dubreuil and Yu (1994) by its sequence and chromosomal location, but more importantly in its expression pattern. The existence of a ubiquitously and a neuronally expressed ankyrin gene in Drosophila is somewhat reminiscent of the situation in mammalian species. In this way, the expression pattern of the Drosophila ankyrin 1 gene is similar to that of ankyrin $_{R}$ and that of Drosophila ankyrin 2 to ankyrin $_{G}$. The phylogenetic analysis presented in Figure 3, however, clearly 

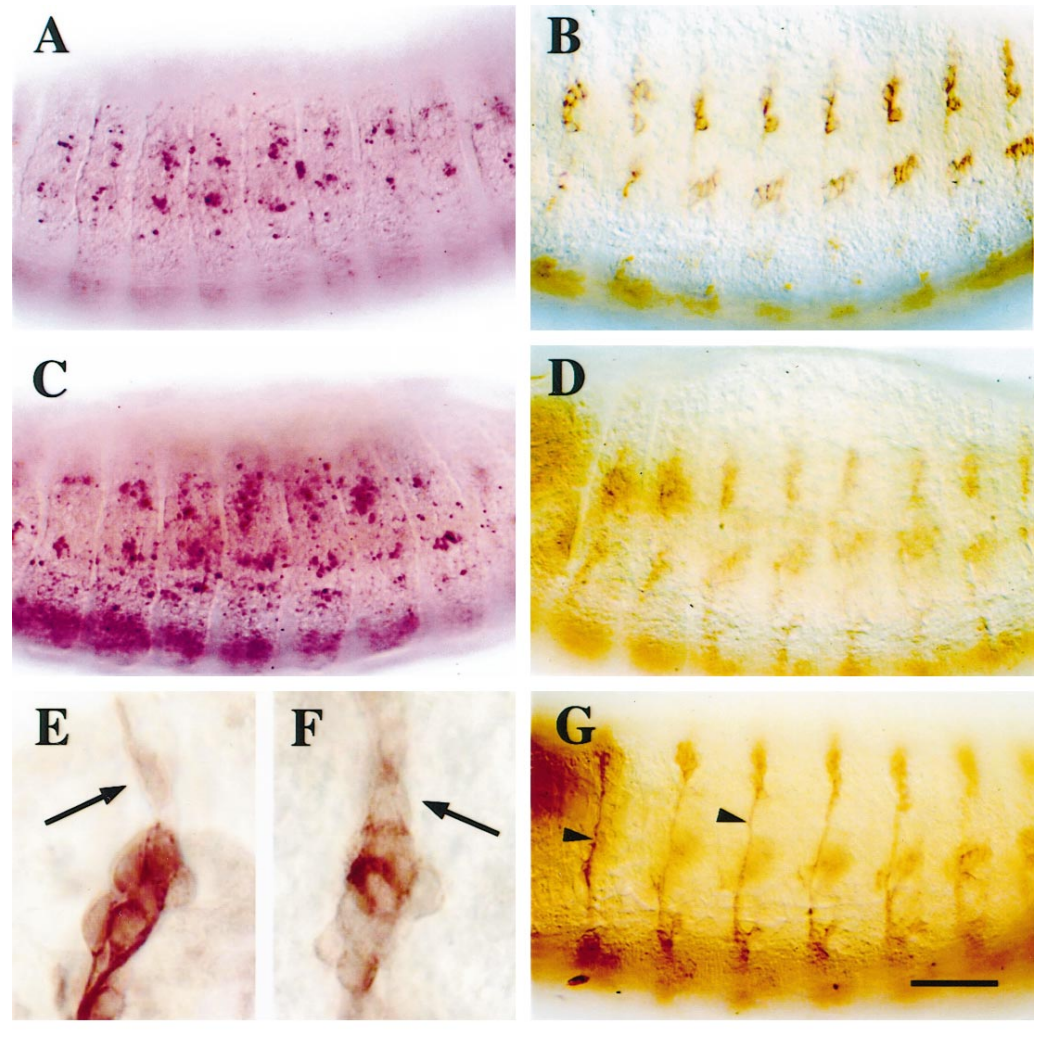

Figure 9. The absence of neuroglian protein decreases Dank2 protein but not mRNA levels. The levels of Dank2 mRNA in the PNS of stage 14 Drosophila embryos were visualized by in situ hybridization using a Dank2 cDNA probe $(A, C)$, whereas the levels of Dank2 protein were assessed by immunocytochemistry using a mouse anti-Dank2 serum $(B, D)$. Whereas wild-type embryos are depicted in $A$ and $B, C$ and $D$ show neuroglian-deficient embryos. $E$ and $F$ each depict a cluster of dmd6 sensory neurons in the PNS of dissected wild-type embryos. Dendritic staining for Dank2 $(E)$ and for neuroglian ${ }^{180}$ $(F)$ is indicated by arrows. The stage 14 wild-type embryo shown in $G$ was stained with the anti-neuroglian ${ }^{180} \mathrm{mAb}$ BP-104. Stained peripheral axonal pathways are marked by arrowheads. Scale bar: $A-D, G, 60 \mu \mathrm{m} ; E, F, 15 \mu \mathrm{m}$.
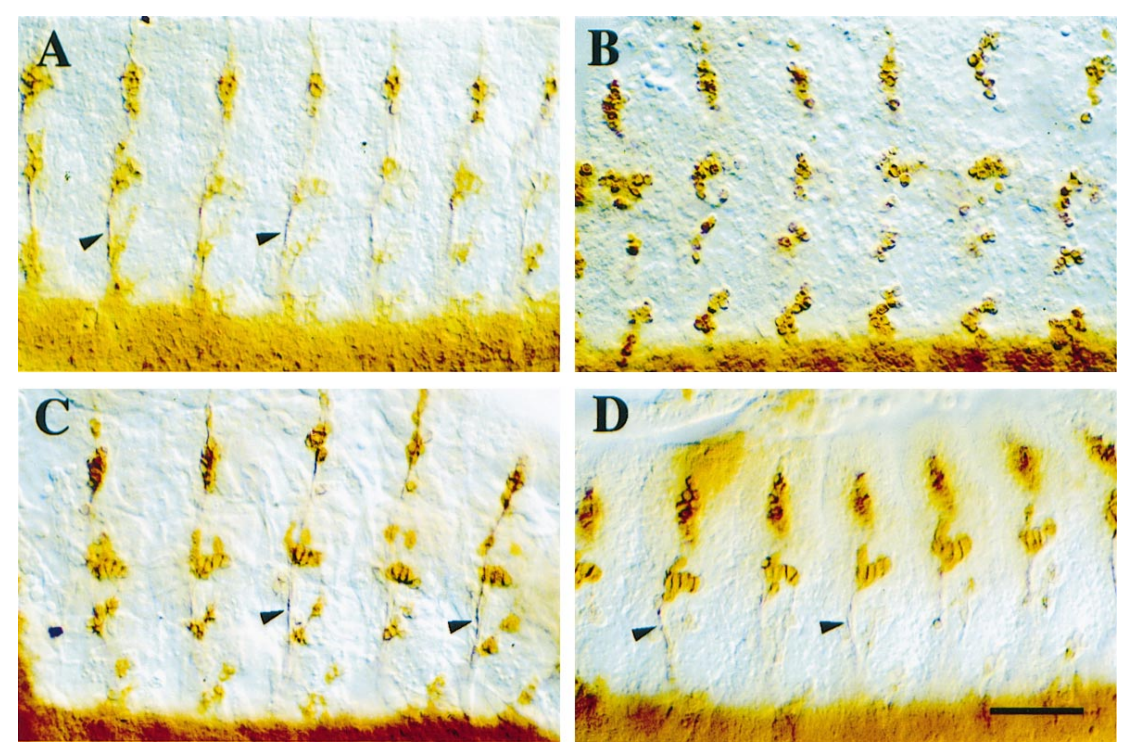

Figure 10. Lack of axonal neuroglian expression does not prevent the axonal localization of Dank2 protein. $A-D$ show embryonic dissections of either wild type ( $A$, $C$ ) or of the temperature-sensitive $n r^{3}$ mutation $(B, D)$. After egg laying, before dissection all embryos were reared at nonpermissive temperature $\left(29^{\circ} \mathrm{C}\right) . A$ and $B$ were stained for $n$ rg ${ }^{180}$ protein using the BP-104 mAb and $C$ and $D$ for Dank2 protein using a mouse antiserum. Arrowheads point out stained axonal tracts in the lateral PNS. Anterior is to the left. Scale bar, $60 \mu \mathrm{m}$.

indicates that the duplication of ankyrin genes in Drosophila occurred independently of the chordate ankyrin gene diversification. One can speculate that the membrane skeleton plays an especially important role in the structural and functional differentiation of neuronal cells and that more complex nervous systems require several, more specialized ankyrin forms. The $C$. elegans genome contains only one ankyrin-type gene (unc-44), and unc-44 mutations result in nervous system-related phenotypes, including aberrant axonal guidance and fasciculation (Otsuka et al., 1995). In a cerebellum-specific knock-out mouse for ankyrin $_{G}$, the L1-type CAM neurofascin and voltage-dependent $\mathrm{Na}^{+}$channels are not properly segregated to the axon initial segments and the nodes of Ranvier of neurons (Zhou et al., 1998). This indicates that ankyrins are involved in the initiation and maintenance of these specialized neuronal membrane domains.

Outside the nervous system, e.g., in the lateral domain of salivary gland epithelial cells, Drosophila ankyrin 1 protein colocalizes with the non-neuronal, $167 \mathrm{kDa}$ form of Drosophila neuroglian (Dubreuil et al., 1997). In neuronal cells, the $180 \mathrm{kDa}$ form of neuroglian appears to be an important binding partner for the neuronally expressed Dank2 protein. Ankyrin protein stability typically correlates with its binding to a specific integral membrane protein and its association with the actin-spectrin 
network (Moon and Lazarides, 1984). In the absence of neuroglian expression, a dramatic reduction of Dank2 protein levels was observed in cells that normally express neuroglian. This observation is consistent with the finding that detergent-soluble pools of ankyrin are rapidly turned over, whereas plasma membrane-associated ankyrin has a significantly longer half-life (Moon and Lazarides, 1984). Similarly, in chicken erythrocytes, which are deficient for the major ankyrin-binding membrane protein AE1, a 50\% reduction of ankyrin level was reported (Peters et al., 1996). The availability of membrane binding sites generally appears to confer ankyrin stability. In Drosophila neurons, this effect does not require neuroglian to be expressed on the cell surface. In embryos, which are homozygous for the temperature-sensitive $\mathrm{nrg}^{3}$ mutation and which develop at the restrictive temperature, neuroglian protein remains associated with an unidentified intracellular organelle and is not transported to the plasma membrane (Hall and Bieber, 1997). Nevertheless, this intracellular expression of neuroglian protein rescues the reduced Dank2 levels observed in neuroglian null embryos. Therefore, Dank2 protein appears to interact with neuroglian at the level of an intracellular compartment, e.g., the Golgi complex or the trans-Golgi network. This interaction is probably only transient, because Dank2 does not remain colocalized with the intracellular $\mathrm{nrg}^{3}$ protein at the restrictive temperature. An intracellular localization of ankyrin protein has also been observed in Drosophila S2 cells, which do not express neuroglian (Dubreuil et al., 1996). In addition, there are several other reports that membrane skeleton components are associated with their membrane-associated binding partners at the level of the Golgi complex (Beck et al., 1994, 1997; Devarajan et al., 1996; Ghosh et al., 1999).

These intracellular interactions are sufficient to stabilize ankyrin expression, but they are not involved in the further transport of Dank2 protein to the axons of Drosophila embryonic neurons. Thus, it now seems unlikely that L1 CAMs are responsible for the long-range recruitment of membrane skeleton elements to localized plasma membrane domains. The observation that the loss of initial axon segment localization for neurofascin and voltage-dependent $\mathrm{Na}^{+}$channels in knock-out mice for anky$\operatorname{rin}_{\mathrm{G}}$ indicates that neuronal ankyrins are a determining factor for the creation of specialized plasma membrane domains containing these membrane proteins (Zhou et al., 1998). Although neuroglian protein is detectable in Drosophila PNS axons slightly earlier than Dank2 protein, it remains possible that the localization of neuroglian protein depends on interactions with the membrane skeleton.

Although neuroglian appears to be an important ankyrin membrane receptor in Drosophila neuronal cells, other ankyrinbinding membrane proteins most certainly do exist. In neuroglian null mutant embryos, Dank2 levels remain high in VUM neurons, and Dank2 protein in these cells is still sequestered at cell-cell contacts. Because VUMs express the engrailed homeobox protein, which is a repressor of neuroglian expression (Siegler and Jia, 1999), they are normally neuroglian-negative and must therefore express one or several different ankyrin-binding membrane proteins. One type of candidate for such an ankyrin membrane receptor in Drosophila neuronal cells might be so far not identified Drosophila homologs of $\beta$-subunits of the voltage-dependent $\mathrm{Na}^{+}$channel. Both $\beta$-subunits of the rat voltage-dependent $\mathrm{Na}^{+}$ channel interact with and recruit Drosophila ankyrin 1 protein to cell contact sites in transfected S2 cells (Malhotra et al., 2000). Although neuroglian interacts with the protein products from both Drosophila ankyrin genes, one might also postulate the existence of ankyrin membrane receptors, which are specific for either of the two Drosophila ankyrins. So far, functional differences have not been identified between Dank1 and Dank2. The identification of any functional variances beyond their different expression pattern might shed light as to why two ankyrin genes have been conserved in the Drosophila genome and what role neuron-specific ankyrins play in the structural and functional organization of neuronal cells in general.

\section{REFERENCES}

Ausubel FM, Brent R, Kingston RE, Moore DD, Seidman JG, Smith JA, Struhl K (1988) Current protocols in molecular biology. New York: Wiley.

Bartel PL, Chien C-t, Sternglanz R, Fields S (1993) Using the twohybrid system to detect protein-protein interactions. In: Cellular interactions in development: a practical approach (Hartley DA, ed), pp 153-179. Oxford: IRL.

Beck KA, Buchanan JA, Malhotra V, Nelson WJ (1994) Golgi spectrin: identification of an erythroid beta-spectrin homolog associated with the Golgi complex. J Cell Biol 127:707-723.

Beck KA, Buchanan JA, Nelson WJ (1997) Golgi membrane skeleton: identification, localization and oligomerization of a $195 \mathrm{kDa}$ ankyrin isoform associated with the Golgi complex. J Cell Sci 110:1239-1249.

Bennett V, Gilligan DM (1993) The spectrin-based membrane skeleton and micron-scale organization of the plasma membrane. Annu Rev Cell Biol 9:27-66.

Bieber AJ, Snow PM, Hortsch M, Patel NH, Jacobs JR, Traquina ZR, Schilling J, Goodman CS (1989) Drosophila neuroglian: a member of the immunoglobulin superfamily with extensive homology to the vertebrate neural adhesion molecule L1. Cell 59:447-460.

Bradford MM (1976) A rapid and sensitive method for the quantitation of microgram quantities of protein utilizing the principle of protein-dye binding. Anal Biochem 72:248-254.

Brown DA, London E (1998) Functions of lipid rafts in biological membranes. Annu Rev Cell Dev Biol 14:111-136.

Burnette WN (1981) "Western blotting": electrophoretic transfer of proteins from sodium dodecyl sulfate-polyacrylamide gels to unmodified nitrocellulose and radiographic detection with antibody and radioiodinated protein A. Anal Biochem 112:195-203.

Campos-Ortega JA, Hartenstein V (1985) The embryonic development of Drosophila melanogaster. Berlin: Springer Verlag.

Church GM, Gilbert W (1984) Genomic sequencing. Proc Natl Acad Sci USA 81:1991-1995.

Craig AM, Banker G (1994) Neuronal polarity. Annu Rev Neurosci $17: 267-310$.

Davis JQ, Lambert S, Bennett V (1996) Molecular composition of the node of Ranvier: identification of ankyrin-binding cell adhesion molecules neurofascin (mucin+/third FNIII domain-) and NrCAM at nodal axon segments. J Cell Biol 135:1355-1367.

Devarajan P, Stabach PR, Mann AS, Ardito T, Kashgarian M, Morrow JS (1996) Identification of a small cytoplasmic ankyrin (AnkG119) in the kidney and muscle that binds beta I sigma spectrin and associates with the Golgi apparatus. J Cell Biol 133:819-830.

Dubreuil RR, Yu J-Q (1994) Ankyrin and beta-spectrin accumulate independently of alpha-spectrin in Drosophila. Proc Natl Acad Sci USA 91:10285-10289.

Dubreuil RR, MacVicar G, Dissanayake S, Liu C, Homer D, Hortsch M (1996) Neuroglian-mediated cell adhesion induces assembly of the membrane skeleton at cell contact sites. J Cell Biol 133:647-655.

Dubreuil RR, Maddux PB, Grushko TA, MacVicar GR (1997) Segregation of two spectrin isoforms: polarized membrane-binding sites direct polarized membrane skeleton assembly. Mol Biol Cell 8:1933-1942.

Ghosh S, Cox KH, Cox JV (1999) Chicken erythroid AE1 anion exchangers associate with the cytoskeleton during recycling to the Golgi. Mol Biol Cell 10:455-469.

Hall SG, Bieber AJ (1997) Mutations in the Drosophila neuroglian cell adhesion molecule affect motor neuron pathfinding and peripheral nervous system patterning. J Neurobiol 32:325-340.

Hortsch M (1994) Preparation and analysis of membranes and membrane proteins from Drosophila. In: Drosophila melanogaster: practical uses in cell biology, Vol 44 (Goldstein L, Fyrberg E, eds), pp 289-301. San Diego: Academic. 
Hortsch M (1996) The L1 family of neural cell adhesion molecules: old proteins performing new tricks. Neuron 17:587-593.

Hortsch M (2000) Structural and functional evolution of the L1-family: are four adhesion molecules better than one? Mol Cell Neurosci 15:1-10.

Hortsch M, Avossa D, Meyer DI (1985) A structural and functional analysis of the docking protein. Characterization of active domains by proteolysis and specific antibodies. J Biol Chem 260:9137-9145.

Hortsch M, Bieber AJ, Patel NH, Goodman CS (1990a) Differential splicing generates a nervous system-specific form of Drosophila neuroglian. Neuron 4:697-709.

Hortsch M, Patel NH, Bieber AJ, Traquina ZR, Goodman CS (1990b) Drosophila neurotactin, a surface glycoprotein with homology to serine esterases, is dynamically expressed during embryogenesis. Development 110:1327-1340.

Hortsch M, Homer D, Malhotra JD, Chang S, Frankel J, Jefford G, Dubreuil RR (1998a) Structural requirements for "outside-in" and "inside-out" signaling by Drosophila neuroglian, a member of the L1 family of cell adhesion molecules. J Cell Biol 142:251-261.

Hortsch M, O'Shea KS, Zhao G, Kim F, Vallejo Y, Dubreuil RR (1998b) A conserved role for $\mathrm{L} 1$ as a transmembrane link between neuronal adhesion and membrane cytoskeleton assembly. Cell Adh Comm 5:61-73.

Kordeli E, Bennett V (1991) Distinct ankyrin isoforms at neuron cell bodies and nodes of Ranvier resolved using erythrocyte ankyrindeficient mice. J Cell Biol 114:1243-1259.

Kordeli E, Lambert S, Bennett V (1995) AnkyrinG. A new ankyrin gene with neural-specific isoforms localized at the axonal initial segment and node of Ranvier. J Biol Chem 270:2352-2359.

Kunimoto M, Adachi T, Ishido M (1998) Expression and localization of brain ankyrin isoforms and related proteins during early developmental stages of rat nervous system. J Neurochem 71:2585-2592.

Lambert S, Davis JQ, Bennett V (1997) Morphogenesis of the node of Ranvier: co-clusters of ankyrin and ankyrin-binding integral proteins define early developmental intermediates. J Neurosci 17:7025-7036.

Lehrach H, Diamond D, Wozney JM, Boedtker H (1977) RNA molecular weight determinations by gel electrophoresis under denaturing conditions, a critical reexamination. Biochemistry 16:4743-4751.
Malhotra JD, Kazen-Gillespie K, Hortsch M, Isom LL (2000) Sodium channel $\beta$ subunits mediate homophilic cell adhesion and recruit ankyrin to points of cell-cell contact. J Biol Chem 275:11383-11388.

Moon RT, Lazarides E (1984) Biogenesis of the avian erythroid membrane skeleton: receptor-mediated assembly and stabilization of ankyrin (goblin) and spectrin. J Cell Biol 98:1899-1904.

Nelson WJ, Beck KA (1999) Ankyrins. In: Guidebook to the extracellular matrix, anchor, and adhesion proteins, 22-26. Oxford: Oxford UP.

Nilsson B, Abrahmsen L (1990) Fusions to staphylococcal protein A. Methods Enzymol 185:144-161.

Otsuka AJ, Franco R, Yang B, Shim KH, Tang LZ, Zhang YY, Boontrakulpoontawee P, Jeyaprakash A, Hedgecock E, Wheaton VI, Sobery A (1995) An ankyrin-related gene (unc-44) is necessary for proper axonal guidance in Caenorhabditis elegans. J Cell Biol 129:1081-1092.

Pebusque MJ, Coulier F, Birnbaum D, Pontarotti P (1998) Ancient large-scale genome duplications: phylogenetic and linkage analyses shed light on chordate genome evolution. Mol Biol Evol 15:1145-1159.

Peters LL, Shivdasani RA, Liu SC, Hanspal M, John KM, Gonzalez JM, Brugnara C, Gwynn B, Mohandas N, Alper SL, Orkin SH, Lux SE (1996) Anion exchanger 1 (band 3) is required to prevent erythrocyte membrane surface loss but not to form the membrane skeleton. Cell 86:917-927.

Rodriguez-Boulan E, Powell SK (1992) Polarity of epithelial and neuronal cells. Annu Rev Cell Biol 8:395-427.

Siegler MV, Jia XX (1999) Engrailed negatively regulates the expression of cell adhesion molecules connectin and neuroglian in embryonic Drosophila nervous system. Neuron 22:265-276.

Smith DB, Johnson KS (1988) Single-step purification of polypeptides expressed in Escherichia coli as fusions with glutathione $S$-transferase. Gene 67:31-40.

Smith S, Giriat I, Schmitt A, de Lange T (1998) Tankyrase, a poly(ADPribose) polymerase at human telomeres. Science 282:1484-1487.

Winckler B, Mellman I (1999) Neuronal polarity: controlling the sorting and diffusion of membrane components. Neuron 23:637-640.

Zhou D, Lambert S, Malen PL, Carpenter S, Boland LM, Bennett V (1998) Ankyrin $_{\mathrm{G}}$ is required for clustering of voltage-gated Na channels at axon initial segments and for normal action potential firing. J Cell Biol 143:1295-1304. 